\title{
Fall of Efrafa com Watership Down: A queda do fascismo através da música
}

Fall of Efrafa with Watership

Down: The downfall of fascism through music

Julio Aied Passos

UFSC / CAPES 


\section{Resumo}

Proponho analisar a música do conjunto Fall of Efrafa como potência de reformulação política, não somente a partir da composição literária, mas também no âmbito da composição harmônica. A obra do conjunto consiste em três álbuns, que formam uma trilogia, em que os pensamentos antifascista e revolucionário, inclusive ao modo de vida humano, são centrais. Para refletir na ação da música na política, utilizo o pensamento de Agamben em La musica suprema, ao ler $A$ República de Platão, de que a música é política e a política é musical. É impossível escapar de uma leitura, nessa mesma direção política, do romance Watership Down, de Richard Adams, no qual a banda não só retira o seu nome, como também se baseia em sua mitologia e narrativa para elaborar suas composições.

Palavras-chave: Música; Política; Fall of Efrafa; Richard Adams.

\section{Abstract}

I propose to analyze the music from the group Fall of Efrafa as a power of political reformulation, not just from the literary composition, but also at the harmonic composition. The band's work consists of three albums, which form a trilogy, where the anti-fascist and revolutionary thinking, including the human's life style, are central. To reflect of the music's action at the politics, I use Agamben's thinking in La musica suprema, while reading Plato's Republic, that music is political and the politics are musical. It's impossible to escape from a reading, at that same political direction, of the Richard Adams' Watership Down, in which the band not only takes its name, but also base in the romance's mythology and narrative to concept their compositions.

Keywords: Music; Politics; Fall of Efrafa; Richard Adams. 
O conjunto musical Fall of Efrafa, durante o período de 2005 a 2009, lançou uma trilogia de discos, intitulada de The Warren ${ }^{1}$ of Snares, composta pelos álbuns Owsla (2006), Elil (2007) e Inlé (2009). Após lançarem o último disco, em 2009, a banda se dissolve. Essa trilogia é baseada no romance Watership Down, de Richard Adams, que se concentra em um grupo de coelhos que decide fugir do agrupamento em que vive. Essa fuga ocorre após uma intuição que ocorre a Fiver, um coelho portador de um certo sexto sentido, enquanto passeia com seu irmão, Hazel. Na caminhada, eles encontram um buraco cavado no chão, uma chapa de madeira contendo linhas negras feitas com tinta e uma estaca de madeira ao seu lado. Fiver se sente mal no momento e logo informa a Hazel: “'Oh, Hazel! This is where it comes from! I know now something very bad! Some terrible thing - coming closer and closer"'2. Logo depois Fiver tem uma visão do campo coberto de sangue. Então ambos decidem avisar o líder da warren de que todos os habitantes correm perigo, e que devem sair do local o mais rápido possível. Mas os dois fracassam em convencê-lo, então decidem fugir imediatamente, com alguns coelhos que acreditam no perigo iminente ${ }^{3}$.

O pequeno grupo de refugiados, liderado por Hazel, ao encontrar no caminho uma sociedade de coelhos que, aparentemente, vive em paz, com comida fácil deixada por humanos, começa a viver nas tocas com os habitantes. Mais tarde, os recém chegados descobrem que o local está cercado por armadilhas para capturar coelhos, e então o grupo de Hazel o batiza de The Warren of Snarest. A maior parte de seus habitantes vive de forma quase anestesiada, automática, sem indagar o motivo da comida fácil, apenas a comem quando ela se apresenta, reagindo de forma imediata, semelhante ao cidadão das grandes cidades modernas, como descrito por Benjamin: "Os transeuntes comportam-se como se, adaptados à automatização, já só conseguissem se exprimir de forma automática. O seu comportamento é uma reação aos choques”. ${ }^{5}$. Uma reação automática, de quem já está acostumado a tais choques, entrando mesmo numa reação ritmada e rápida, análoga à vivência do operário junto da máquina que ele opera, "a peça que lhe cabe surge no raio de ação do operário independentemente da sua vontade"

1 A palavra inglesa warren indica um complexo de buracos e túneis subterrâneos onde vivem os coelhos. Por falta de uma palavra em língua portuguesa que a traduza com precisão o sentido que possui no romance, utilizarei a palavra warren ao longo do texto.

2 ADAMS, Richard. Watership Down, 2012, p 7.

3 O que Hazel e Fiver encontraram, e não puderam decifrar, é revelado ao leitor com uma placa que contém o anúncio: “THIS IDEALLY SITUATED ESTATE, COMPRISING SIX ACRES OF EXCELLENT BUILDING LAND, IS TO BE DEVELOPED WITH HIGH CLASS MODERN RESIDENCES BY SUTCH AND MARTIN, LIMITED, OF NEWBURY, BERKS.” Ibidem. p. 8.

4 Algo como "Warren das armadilhas".

5 BENJAMIN, Walter. "Sobre alguns motivos na obra de Baudelaire”, 2015, p. 130.

6 Ibidem. p. 128. 
Os habitantes de Warren of snares vivem de forma análoga, nem mesmo questionam o desaparecimento de alguns coelhos de forma abrupta, quando capturados pelas armadilhas implantadas pelos humanos ${ }^{7}$.

Observo que esses coelhos estão absortos no imediatismo, e vivem alheios ao passado remoto, ou mesmo à cosmogonia e aos mitos, característica que se torna clara na relação entre eles e os refugiados, principalmente quando Dandelion, contador de histórias do grupo de Hazel, narra um dos feitos de El-ahrairah, o primeiro coelho criado no mundo por Frith, entidade análoga ao Deus cristão, no conto intitulado The story of King Lettuce. A narrativa se concentra em um momento de dificuldade para Elahrairah e seus companheiros, obrigados pelos outros animais a viver nos pântanos, onde há pouco alimento. Para reverter a situação, El-ahrairah propõe uma aposta a Prince Rainbow, coelho enviado por Frith: caso ele consiga roubar as alfaces do jardim de King Darzin, Rainbow deverá libertar seu grupo dos pântanos.

Para a missão, El-ahrairah envia o chefe de sua Owsla ${ }^{8}$ como infiltrado ao palácio para estragar o alimento nos depósitos. Após alguns dias com o rei adoentado, El-ahrairah, disfarçado de médico para enganar a guarda real, dirige-se ao palácio e demanda ver Darzin, dizendo ter sido enviado por Prince Rainbow ${ }^{9}$. Ao se encontrar com o rei, El-ahrairah exige examinar tanto a dispensa quanto o jardim de alface e, após sua análise, afirma que o motivo da doença do rei são as próprias alfaces ${ }^{10}$, que estão infectadas com um vírus letal. El-ahrairah propõe que o rei se livre de todas elas, mas em toda sua sabedoria, o rei lhe diz para levar toda a plantação aos coelhos que vivem nos pântanos, para infectá-los e, assim, livrar-se deles. Portanto El-ahrairah ilude o rei que acredita em sua esperteza, sem saber que sua ação irá beneficiar os coelhos que deseja eliminar. Dessa maneira o plano funciona, e o grupo de El-ahrairah se livra da situação desfavorável nos pântanos.

Ao final da narração, Cowslip, chefe da warren, responde: “'Well, we don’t like the old stories very much,' said Cowslip. 'Our stories and poems are mostly about our own lives here""11. Tal resposta traz à tona tanto o conformismo, oposto à atitude de El-ahrairah, quanto o esquecimento da população, eles preferem se estabelecer no imediatismo dos acontecimentos, vivendo em uma bolha de olvidamento, ou seja, eles

7 ADAMS, Richard. Ibidem. p. 113.

8 Espécie de guardas das warrens.

9 "What is the sickness of a little king to the chief physician of the land beyond the golden river of Frith? I will return and tell Prince Rainbow that the king's guard were foolish and gave me such treatment as one might expect from a crowd of flea-bitten louts." Ibidem. p. 95.

10 "When he came back, he looked very grave and said, "Great King, I know well what sorry news it will be to you, but the cause of your sickness is those very lettuces by which you set such store."” Ibidem. p. 95.

11 Ibidem. p. 99. 
se fixam ao presente e nada comentam sobre a sua situação de escravidão perante os humanos. De acordo com Bergson, em Matéria e memória, o sujeito não vive nem somente fixo no presente, respondendo automaticamente, tampouco fixo no passado, como um sonhador: é entre esses dois extremos, passado e presente, que "situa-se a favorável disposição de uma memória bastante dócil para seguir com precisão os contornos da situação presente, mas bastante enérgica para resistir a qualquer outro apelo"12. O sujeito permanece em movimento entre o presente, instante sem extensão, e toda a memória acumulada, o passado. Ou seja, enquanto os coelhos fugitivos permanecem em deslocamento, trazendo ao presente contos do passado, numa influência mútua dos tempos, os coelhos de warren of snares não praticam esse intercâmbio, permanecendo isoladamente no instante presente.

Após esta introdução, analisarei aqui principalmente a peça musical intitulada Beyond the veil, presente no segundo álbum da trilogia. Ela vem como oposição, uma música de resistência à pressa e à falta de indagações, de reflexões, em que o primeiro reflexo rápido, aquela ação imediata que não percorre a totalidade da memória, é o que impera, assim como uma forma de resistência contra a violência do fascismo. Isso já está explícito na composição literária da peça, nas primeiras estrofes:

\footnotetext{
In our haste we crowned a king.

In our haste we bore his sin.

In our haste we saw him God.

In our haste; born again ${ }^{13}$.
}

Na pressa e na ação automática, escolhe-se um rei, um líder, um deus soberano, para nele confiar a escolha das ações a todos, e a todos comandar. Mas para além da composição literária, acredito que a composição instrumental da peça seja tão rica quanto, pela escolha das combinações, montagens de notas e compassos (a variação entre um compasso binário e um quaternário), o andamento musical e sua alternância. O primeiro movimento da peça inicia-se com o som da chuva ${ }^{14}$, que lentamente dá

12 BERGSON, Henri. Matéria e memória: ensaio sobre a relação do corpo com o espirito, 2006, p. 179.

13 "Beyond the Veil". Fall of Efrafa. In: Elil. Brighton: Fight for Your Mind, Alerta Antifascista, Behind the Scenes, Halo of Flies, Denovali Records Tadpole Records, 2007. A letra pode ser conferida em: http://www.darklyrics.com/lyrics/fallofefrafa/elil.html\#1 (acessado em 28 de março de 2020).

14 Este som é continuação do final da música Fall of Efrafa, que fecha o primeiro álbum, Owsla. Beyond the veilé a música de abertura do segundo álbum, Elil. 
lugar para a guitarra sem distorção, que executa uma vez a frase em pianíssimo e em adágio. O compasso é binário composto, $6 / 8^{15}$.

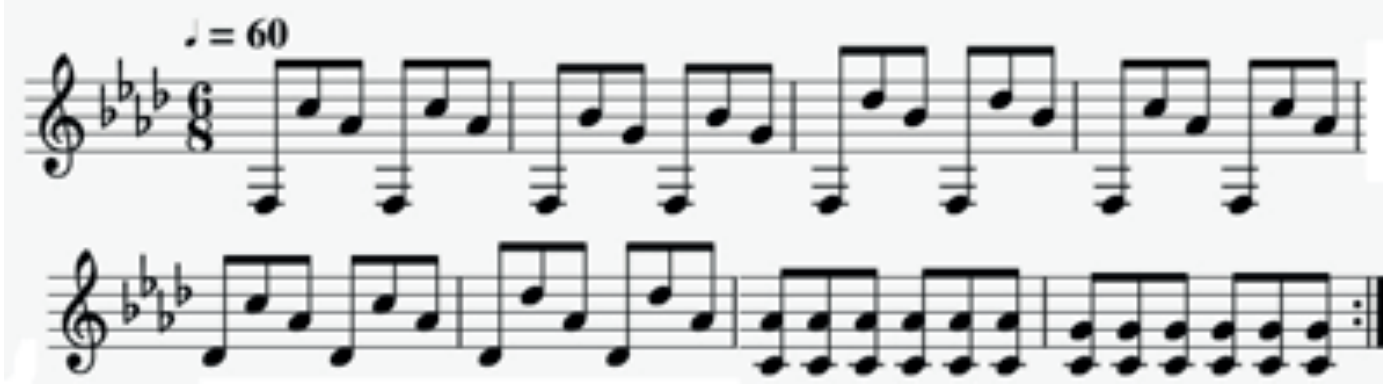

Fig. 1

A guitarra executa essa frase mais uma vez, com uma alteração no último compasso: uma semibreve pontuada, ocupando assim o compasso todo, mantendo as mesmas notas simultâneas, dó e fá, até metade do compasso, alterando para dó e sol. A frase é repetida, e dessa vez é acompanhada de uma narração, uma citação retirada de Watership Down, que termina na semibreve pontuada:

All the world will be your enemy, Prince with a Thousand Enemies, and whenever they catch you, they will kill you. But first they must catch you, digger, listener, runner, prince with the swift warning. Be cunning and full of tricks and your people shall never be destroyed ${ }^{16}$.

A citação em questão é proferida por Frith para El-ahrairah. No romance ela é dita por Dandelion. Introduz-se assim a mitologia que circunda o romance e em que, não só essa peça, mas também o conjunto musical está imerso. A frase recitada faz um jogo entre as notas e suas oitavas, como no primeiro compasso, que vale também para os compassos seguintes. E logo após a percussão entra na música, da mesma forma que a guitarra, executada em pianíssimo, com o mesmo andamento em adágio, a 60bpm:

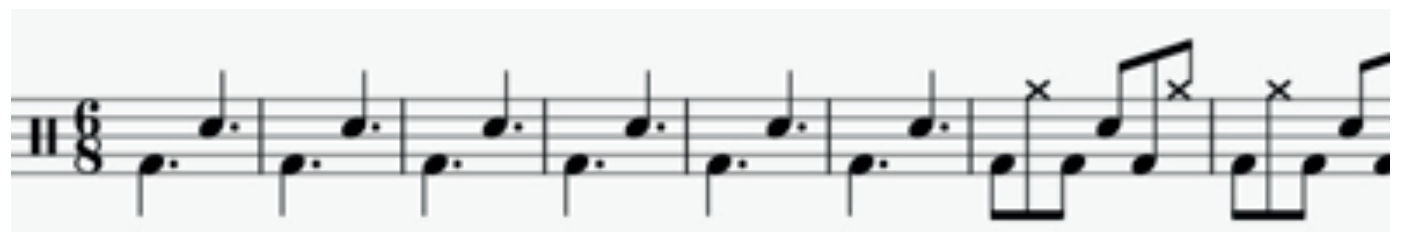

Fig. 2

15 Agradeço ao professor e amigo Felipe Soares pela ajuda na escrita da partitura.

16 ADAMS, Richard. Ibidem. p. 28. 
Nesse primeiro movimento introdutório as modificações são poucas, mas significativas. A música assume a execução de poucas notas, alternando da mesma forma, até o compasso 48, em que a semibreve pontuada reaparece na guitarra em dó e sol, e na bateria executando-a no chimbal aberto. Nos compassos seguintes são repetidos os compassos da guitarra, o baixo cessa, e a bateria mantém-se executando o prato de condução e o bumbo simultaneamente em colcheia. A mudança mais significativa é observada na dinâmica que, do compasso 49 ao 112, vem num crescendo até chegar, do pianíssimo, ao fortíssimo. Esse crescendo de 63 compassos, unido às alternâncias e repetições das notas, como já dito acima, é uma forte oposição ao imediatismo da cultura moderna, em que habitam aqueles que somente respondem ao choque, ao golpe direto, de forma rápida, com outro golpe. A dinâmica da música não chega a dar um choque, é algo que vai se construindo aos poucos. É uma ótima resposta de oposição às ações violentas, que se dão em formas de choques e golpes, ou seja, é uma ação que não imita a violência. Voltarei mais à frente nesse tema.

A guitarra entra de forma distorcida e, na metade do primeiro compasso após a mudança, o vocal, voz única, é introduzido, também em fortíssimo, e aí está a forma significativa em que a execução musical e a mixagem estão presentes na montagem da peça: os instrumentos (considero também a voz) nunca ultrapassam os outros em volume, isso apesar mesmo de o vocal ser em berro quase gutural, o que faz uma combinação firme com a guitarra distorcida, e com os pratos da bateria sempre executados em ataque e fortíssimo, na mesma dinâmica dos demais instrumentos, sendo um pensamento político importante na composição dessa música, uma relação horizontal entre os instrumentos, sem hierarquias. Nenhum deles sobressai, ou seja, não há soberania. Uma montagem sólida. A voz segue o andamento da música, prolongando as palavras com o prolongamento das notas repetidas, seguindo a tonalidade da guitarra e o ritmo dos demais instrumentos.

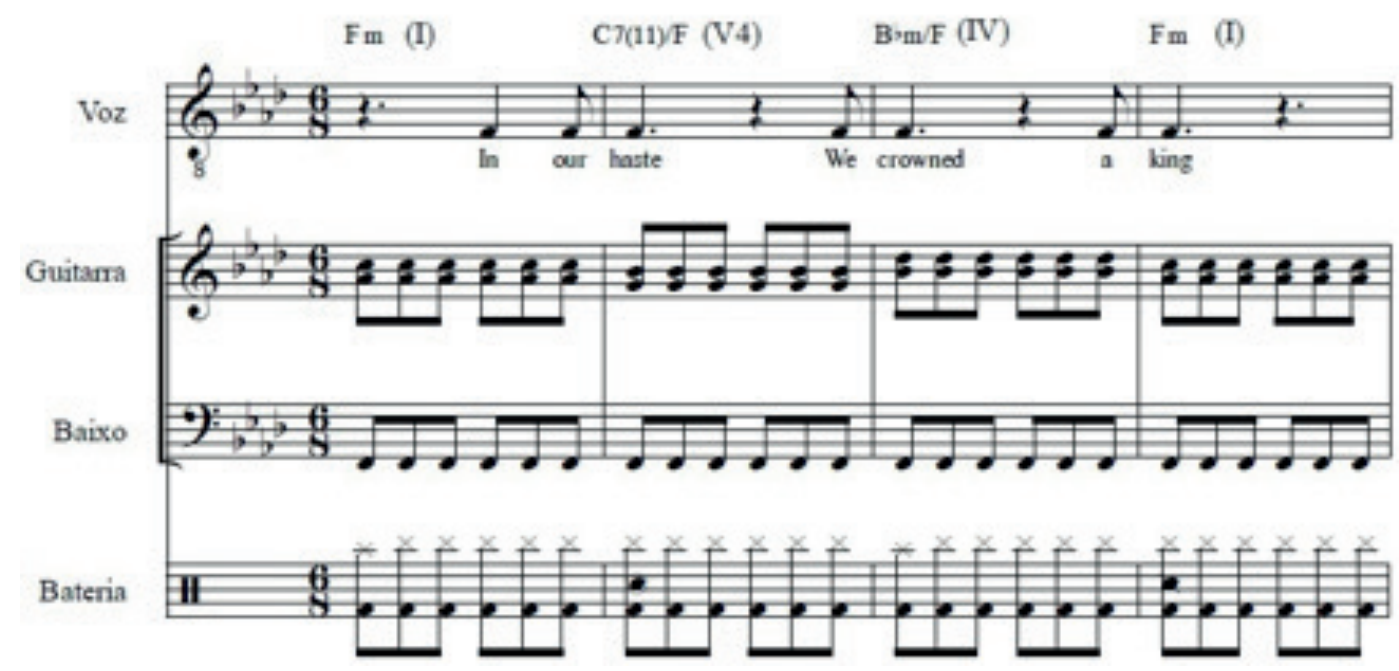

Fig. 3 


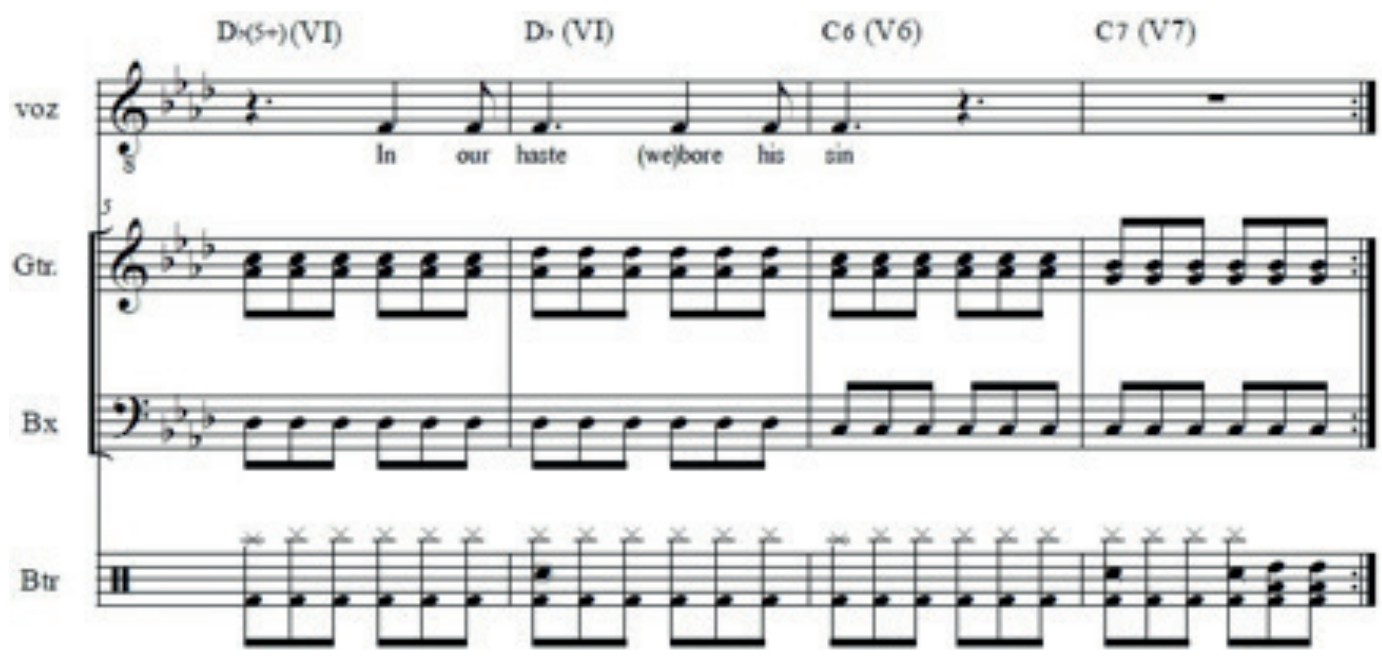

Fig. 4

A guitarra e o baixo repetem essa frase duas vezes, a bateria altera no último compasso, adiantando as duas colcheias que executam simultaneamente o surdo, o tom e o bumbo para metade do primeiro tempo, e início do segundo. A partir da metade do segundo tempo e o terceiro tempo completo, executam-se seis semicolcheias na caixa, como pode ser observado no trecho da partitura:

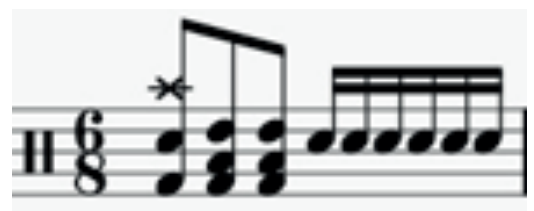

Fig. 5

Em seguida, há mudança no ritmo, mantendo-se as notas da guitarra e do baixo, mas nos dois primeiros tempos de cada compasso, acrescentam-se duas semicolcheias no lugar de uma colcheia, sendo acompanhado por uma mudança igual na bateria; alterando sutilmente, dessa forma, o ritmo, deixando a música menos "dura" e mais dinâmica, utilizando um jogo de notas nos contratempos dos compassos. No caso da bateria, utilizando mais as outras peças do instrumento: 

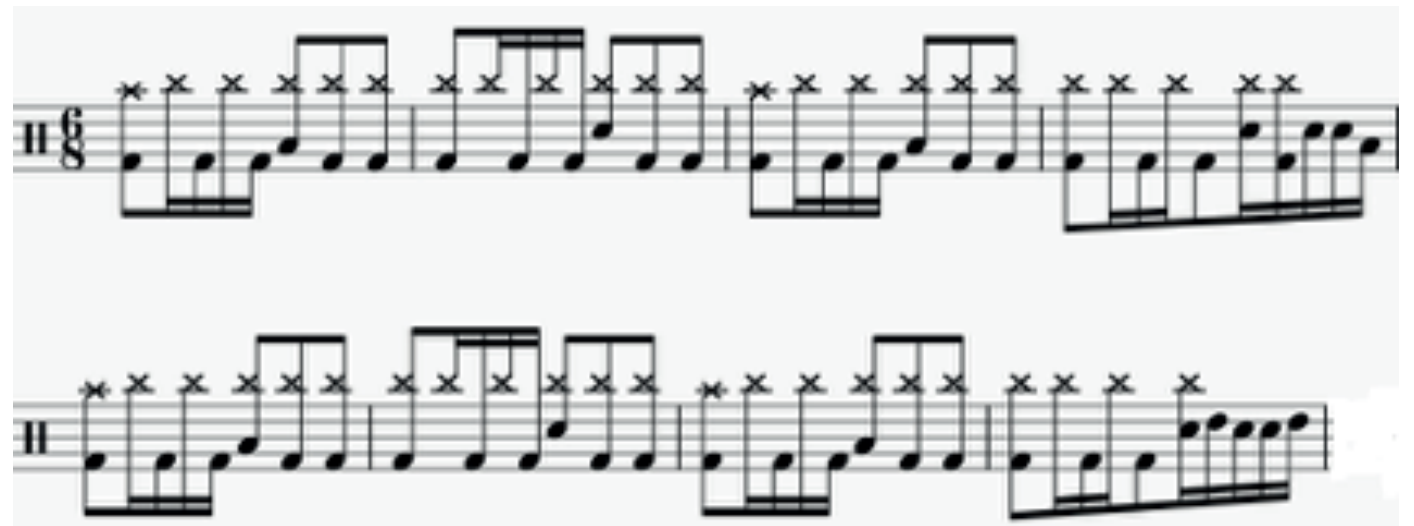

Fig. 6

As mudanças dessas mesmas naturezas, ritmo, dinâmica e também tempo, continuam presentes em toda a música, enquanto as notas executadas continuam, em sua maioria, as mesmas, alterando somente as oitavas e os acidentes. Há uma grande mudança com relação ao tempo, no momento em que o compasso transforma-se de ternário em quaternário, mas como todas as alterações na peça, ela não ocorre como golpe, não vem com um choque, é novamente na sutileza; o andamento caí de forma progressiva nos compassos precedentes à mudança, chegando a 25bpm. E então o que pode ser considerado um primeiro choque na peça, o andamento sobe para andantino, $75 \mathrm{bpm}$, mas o choque é amenizado pelo uso das peças mais graves da bateria, deixando a transição sonora menos brusca. No exemplo abaixo, os dois últimos compassos da bateria e o primeiro após a mudança para quaternário:

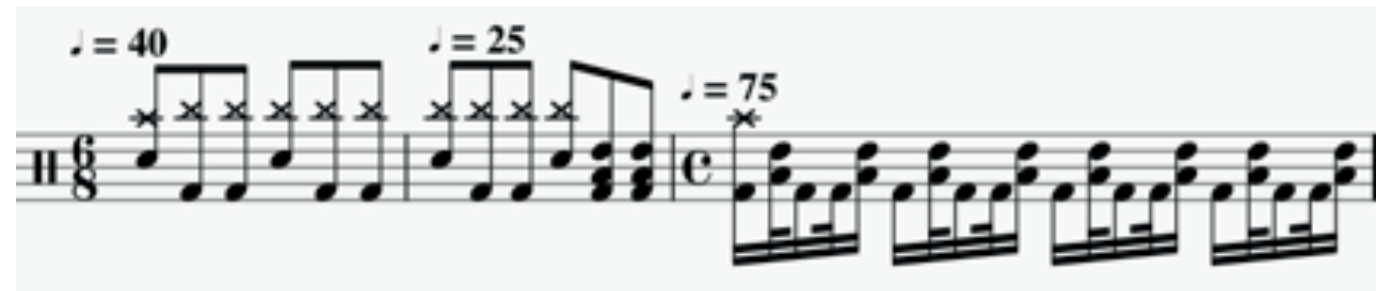

Fig. 7

A música explora as possibilidades nestes aspectos; ela eventualmente voltará ao compasso binário composto, transformando uma composição que poderia cair em um padrão repetitivo, no sentido dos movimentos do operário diante da máquina, através das poucas notas executadas, em uma música quebrada pelas alterações pontuais. A composição é astuta e cheio de truques (cunning and full of tricks, assim como El-ahrairah), alterando pelos meandros do compasso, sendo neste aspecto importante politicamente, diferindo-se dos habitantes de Warren of snares, que vivem em um conformismo eterno, aceitando a morte nas armadilhas. Como escreve Benjamin em Sobre o conceito da História, tese XI: "O conformismo que desde sempre foi apanágio da social-democracia prende-se não apenas com a sua tática política, mas também 
com as suas idéias econômicas" ${ }^{17}$. O detentor do poder tem só a ganhar com esse conformismo. No caso de Warren of snares, os humanos ganham com tal atitude dos coelhos habitantes, conformismo unido ao esquecimento de suas antigas lendas, a perda do contato com as musas, a inspiração musaica pois, como visto mais acima, eles apenas narram fatos cotidianos entre si, mas nada sobre as armadilhas, desprovidos de música. Eles perderam o contato que os leva aos limites da linguagem (algo que o grupo de Hazel e a banda Fall of Efrafa não perderam). É às musas que o poeta pede autorização para poetizar: "Pelas Musas heliconíades comecemos a cantar"". Por elas e através delas o canto surge a Hesíodo:

Elas um dia a Hesíodo ensinaram belo canto quando pastoreava ovelhas ao pé do Hélicon divino ${ }^{19}$.

Como explica Agamben: "Se trata, según toda evidencia, de insertar el yo del poeta como sujeto de la enunciación en un contexto en el cual el inicio del canto pertenece decididamente a las Musas y está, sin embargo, proferido por el poeta"20. São as musas que iniciam o canto, elas são o início para o poeta, simbolizando a impossibilidade da linguagem ao ser falante ${ }^{21}$, que apenas fala sem tocar o limite da linguagem, como os habitantes de Warren of snares, impossibilitando assim a música, e mesmo a filosofia pois, como lembra ainda Agamben, Platão trata a filosofia como "música suprema". Ainda para Agamben a política encontra-se no mesmo lugar do limite da linguagem, pois música e política estão estreitamente ligadas: "Los hombres se unen y organizan las constituciones de sus ciudades a través del lenguaje, pero la experiencia del lenguaje — en cuanto no es posible aferrarla y controlar su origenestá a su vez musicalmente condicionada" ${ }^{\prime 2}$. Para Platão, a mudança musical era extremamente perigosa para a cidade, como ele mesmo afirma n'A República:

A introdução de um novo gênero de música deve ser evitada com o maior empenho, como particularmente perigosa para o todo, pois em parte alguma as leis da Música são alteradas sem que concomitantemente se

17 BENJAMIN, Walter. "Sobre o conceito da História”, 2016, p. 15.

18 HESÍODO. Teogonia, 1995. vv. 1. p. 88.

19 Ibidem. vv. 22-23. p. 89.

20 AGAMBEN, Giorgio. La musica suprema. (de __. Agamben, Giorgio. Che cos'è la filosofia? Macerata: Quodlibet, 2016, p. 133-146. Seção I. Disponível em: < https://ficciondelarazon.org/2016/04/11/ giorgio-agamben-la-musica-suprema-musica-y-politica/ > . Acesso em 26 mar. 2020.

21 Ibidem. Seção II.

22 Ibidem. Seção III. 
modifiquem as leis fundamentais da comunidade, como afirma Damão e eu o creio. $(424 \mathrm{c})^{23}$

O destino destes tristes habitantes que perderam a música, a permissão de acesso ao limite da linguagem, não parece nada promissor. Dessa forma Raúl Antelo afirma que "a sensação de geral depressão e apatia não faz mais do que registrar a perda do nexo musaico com a linguagem, travestindo, como uma síndrome médica, o eclipse da política que é seu resultado" 24 . A impossibilidade de uma música que toque o limite da linguagem permite a decadência política. No caso, o grupo de Hazel ainda tem esse acesso, a eles as musas se apresentam e lhes cantam as histórias primevas. $\mathrm{Na}$ música Beyond the veil fica claro o contato com as musas desde o início, com a música emergindo da natureza, assim como a fala que surge de Frith, figura divina, a El-ahrairah. Ou seja, seguindo Agamben, tais palavras são proferidas pelas musas, e se inserem na música por intermédio do poeta. As mudanças musicais nos meandros, na surdina do compasso, também deixam claro o nexo musaico, pois com essas mudanças musicais a política também pode ser modificada e reconfigurada.

Este nexo musaico, e a ligação entre música e política ficam claros quando, após o grupo de Hazel conseguir fugir de Warren of snares, e fundar uma sociedade própria em local seguro e com abundância de alimentos, batizada de Watership down, eles se vêem frente a frente com uma outra sociedade, chamada Efrafa, comandada pelo general Woundwort. O encontro entre os grupos acontece quando os membros de Watership down se vêem com uma população com pouco número de fêmeas, e sabendo da imensa população presente em Efrafa, um pequeno bando decide falar, de forma diplomática, com Woundwort e pedir autorização para recrutar os coelhos que desejarem viver em Watership down. A negociação é um fracasso, e o pequeno grupo é aprisionado. Antes de conseguirem fugir ficam sabendo, através dos habitantes, que a sociedade é fechada, e ninguém, por motivos de segurança, tem permissão de sair sem um supervisor selecionado por Woundwort, e somente em um pequeno perímetro para se alimentar; como relata Holy, um dos coelhos da expedição que saiu de Watership down, quando retorna: "Most of them can't do anything but what they are told. They've never been out of Efrafa and never smelt an enemy" ${ }^{25}$. Eles são prisioneiros do Estado fascista de Efrafa com pretextos de segurança. O detentor do poder se aproveita do conformismo e do medo de seus súditos e, assim, exerce esse poder da forma que bem entender, no caso com violência, como escreve Benjamin, em Crítica do poder como

23 PLATÃO. A República, 2000, p. 192.

24 ANTELO, Raúl. Exceção, meios, mediação. Conferência proferida na UFSC em set. 2016.

25 ADAMS, Richard. Ibidem. p. 232. 
violência: "todo poder, enquanto meio, tem por função instituir o Direito ou mantêlo"26. Importante lembrar que o termo "Gewalt", utilizado por Benjamin, designa tanto "poder" como "violência" ou "força", ou seja, a violência tem por função tanto instituir como manter o Direito, as leis do Estado.

Após o relato dos membros da expedição, Hazel decide resgatar alguns membros de Efrafa. Para isso ele idealiza um plano digno de El-ahrairah ${ }^{27}$, ouvindo a mensagem de Frith, "be cunning and full of tricks", opondo-se à violência, com truques e sendo astuto, e não com violência. Para a missão de resgate, Hazel envia Bigwig, antigo líder da Owsla, como infiltrado, e assim planejar a fuga junto das coelhas fêmeas que desejam se livrar de Efrafa. Durante a partida eles são seguidos e confrontados por Woundwort e seus soldados, até conseguirem escapar, com ajuda de Kehaar, uma gaivota que mantém amizade com o grupo de Hazel, durante uma tempestade em um barco, onde Hazel e alguns dos coelhos aguardam. Em determinado momento da fuga eles precisam abandonar o barco e nadar, apesar da inaptidão aquática dos coelhos, que conseguem nadar apenas por um percurso pequeno ${ }^{28}$.

Poucos dias após voltarem à Watership Down, os coelhos tomam conhecimento de que uma tropa vinda de Efrafa se aproxima, e um ataque, comandado pelo próprio Woundwort, acontecerá em breve. O plano para vencer as forças de Efrafa surge para Hazel após mais uma das experiências de Fiver: “there's something I'm trying to hear - something the others can't hear. Only I can't hear it either. But it's close. Deep. Leafdrift, deep. I'm going away, Hazel - going away.' His voice grew slow and droway. 'Falling. But it's cold. Cold"'29. Hazel se lembra do cachorro que vive em uma fazenda próxima, e seu plano consiste em soltar e conduzi-lo a Watership Down, fazendo-se de isca, juntamente com outros dois coelhos. Dessa forma o cachorro faria o serviço de se livrar dos soldados de Efrafa. Ou seja, os coelhos utilizarão um elil (palavra na língua dos coelhos que designa os seus predadores), enganando-o para defender sua warren, um plano digno de El-ahrairah: Hazel enxerga as possibilidades próximas e as utiliza em seu favor. Portanto ele manipula um inimigo em comum para expulsar os atacantes, ao invés de utilizar a força militarizada, a maneira violenta de Woundwort, para assim não se igualar a ele. Hazel usa as habilidades que os coelhos herdaram de Elahrairah, aproveitando qualquer brecha à disposição no ambiente. De forma análoga,

26 BENJAMIN, Walter. “Crítica do poder como violência”, 2016, p. 69.

27 ADAMS, Richard. Ibidem. p. 248.

28 "The gull was surprised. 'Dog sveem, rat sveem. You no sveen?'

"Yes, we can swim as long it's not very far." Ibidem. p. 373.

29 Ibidem. p. 426. 
a composição de Beyond the veil, que faz suas mudanças nos detalhes, vendo as lacunas que a composição musical propicia para explorar as partituras.

O plano funciona e Woundwort foge de Watership Down com o cachorro em seu encalço. Apesar do sumiço do general, e do retorno do cão à fazenda, nenhum dos coelhos acredita em sua morte, Woundwort provavelmente se retirou para a mata, sem força suficiente para enfrentar ninguém, nem mesmo para retornar à Efrafa. Dessa forma, na ausência de Woundwourt, Efrafa cai como um Estado autoritário, transformando-se numa warren pacífica, mantendo relações diplomáticas com Watership Down, em que ambas as populações convivem conjuntamente ${ }^{30}$. Essa escolha pela não imposição da força é de extrema importância política, pois vinculada à ideia de ligação do poder com violência, é uma forma de realmente mudar o sistema político. Não havendo violência, não há poder, esvazia-se assim a figura de um soberano. Nietzsche, na primeira dissertação de Genealogia da moral, escreve sobre a relação de poder entre a nobreza, "bom", e os plebeus, ou todo o resto, "ruim"31. O valor da nobreza esteve no poder até a instauração do cristianismo (vale lembrar que Nietzsche escreve sobre o ocidente) que inverte o valor, o "bom" passa a ser a simplicidade, e a nobreza o "ruim". Dessa forma entram em conflito pelo poder a moral do ressentido e a moral nobre. "A moral escrava sempre requer, para nascer, um mundo oposto e exterior, para poder agir em absoluto - sua ação é no fundo reação"32. Nessa luta há somente inversão de valores, mas o sistema de poder/violência continua, como no exemplo dado por Nietzsche da Revolução francesa, que derruba o poder da nobreza francesa, e das massas ressentidas que a derrubam, surge Napoleão, "o mais único e mais tardio dos homens, e com ele o problema encarnado do ideal nobre enquanto tal - considere-se que o problema é este: Napoleão, esta síntese de inumano (plebeu) e sobre-bumano (nobre)"33.

Uma alternativa para resolver a inversão de valores em uma revolução surge nas correspondências trocadas entre Gandhi e Tolstói, nas quais o escritor russo escreve muito sobre a teoria da não-violência. $\mathrm{Na}$ última destas cartas, Tolstói escreve a Gandhi sobre um interrogatório feito por um professor de catecismo e um bispo, sobre os mandamentos, em um instituto feminino, em Moscou:

30 "The efrafans survivors had been allowed to join the warren and after a shaky start, when they were regarded with dislike and suspicion, were settling down pretty well, largely because Hazel was determined that they should." Ibidem. p. 463.

31 NIETZSCHE, Friedrich. Genealogia da moral: uma polêmica, 1998, p. 21.

32 Ibidem. p. 29.

33 Ibidem. p. 45. Grifo no original. 
Depois das respostas corretas sobre esse mesmo assunto, o bispo costumava perguntar se o assassinato era sempre proibido pela lei de Deus, não importando as circunstâncias. E, corrompidas por seus mestres, as infelizes moças deviam responder - e respondiam - que nem sempre, que o assassinato era permitido na guerra e para castigar os criminosos. No entanto, após responder, a uma daquelas infelizes moças (e o que relato aqui não é mentira, mas um fato que me foi transmitido por uma testemunha) foi feita a habitual pergunta: o assassinato é sempre um pecado? Emocionada e ruborizada, ela respondeu com firme convicção que "sempre". E, a todos os costumeiros sofismas do bispo, ela respondia com convicção firme que o assassinato é sempre proibido, e que ele havia sido proibido já no Velho Testamento, e também por Cristo, e que, não somente o assassinato, mas todo tipo de mal contra o próximo. E, apesar de toda a sua grandeza e eloquência, o bispo calou-se, e a moça saiu vitoriosa. ${ }^{34}$

A moça interrogada defendeu a não-violência de forma não-violenta, e não importando o poder que o bispo possa ter, ali, naquele instituto, frente a frente com a moça, esse poder de nada valia, foi anulado. A mulher utiliza, inclusive, como aporte de defesa da não-violência, os escritos da Bíblia que, claramente, o bispo havia ignorado para justificar os atos violentos do Estado e da Igreja.

No caso de optar pela não-violência, opta-se também pelo não-poder, utilizando truques e formas de enganar o soberano, deixando-o impotente. Uma revolução sem hierarquias, tal qual aparece na montagem de Beyond the veil, como dito mais acima: os instrumentos não sobressaem sobre os outros; são como vozes diferentes falando no mesmo volume. Há inclusive um trecho em que a dinâmica, que estava em fortíssimo, passa para piano, quase repetindo o primeiro movimento na guitarra, acrescida de distorção e ligaduras, e a voz, mesmo que sempre cantando em berro, acompanha a mudança, como se a voz agora cantasse sem o auxílio da ampliação do microfone, ela surge das profundezas acompanhando os sons.

34 TOLSTÓI, Lev; GANDHI, Mahatma. "Correspondência entre L.N. Tolstói e M.K. Gandhi”, 2008, p. 112. 


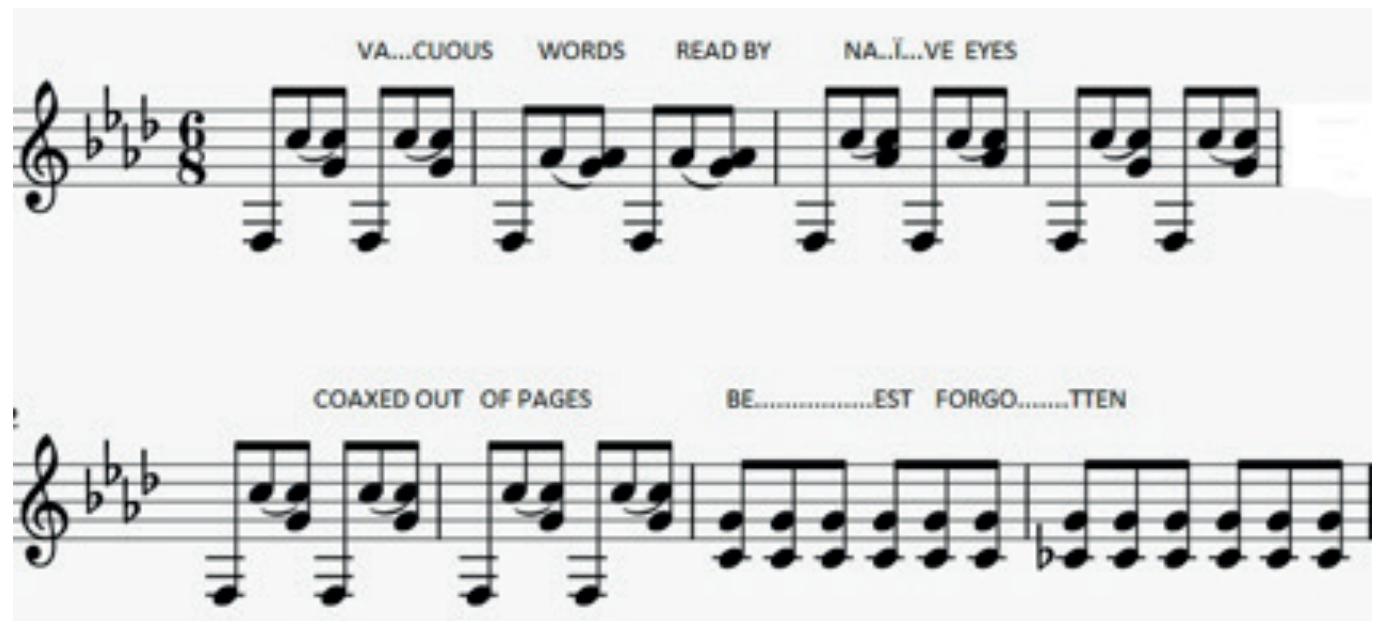

Fig. 8

Em outra música, intitulada Last but not least, do primeiro álbum, a ausência de hierarquias fica clara em seus versos finais, como também o uso da violência pelo fascismo, e dos truques para anulá-lo:

\footnotetext{
Foreboding fates will not cease.

Laying my death before me.

Arrows split against my hide.

I am everyone, everyone in these eyes.

I will witness, witness the fall of Efrafa!

I will witness, witness the fall! ${ }^{35}$
}

No momento em que a vOz grita "witness the fall of Efrafa", mais vozes surgem e gritam junto com a primeira. Nesse sentido, as vozes surgem em comunhão como defesa aos ataques violentos, e aquele que observa escondido, combate a violência de forma sorrateira, e testemunha a queda do fascismo, o faz com toda a comunidade, pois ele deixa de ser um indivíduo isolado, tornando-se um sujeito coletivo (I'm everyone in these eyes). Dessa forma, contra uma sociedade fascista, do poder/violência, surge uma comunidade, nos moldes em que Nancy escreve, em $A$ comunidade inoperada:

35 LAST BUT NOT LEAST. Fall of Efrafa. In: Owsla. Brighton: Fight for Your Mind, Alerta Antifascista, Behind the Scenes, Halo of Flies, Denovali Records Tadpole Records, 2005. A letra pode ser conferida em: http://www.darklyrics.com/lyrics/fallofefrafa/owlsa.html\#5 (acessado em 20 de março de 2020). 
distinta da sociedade (que é uma simples associação e repartição de forças e de necessidades) bem como que em oposição ao controle (que dissolve a comunidade ao submeter seus povos às suas armas e à sua glória), a comunidade não é apenas a comunicação íntima de seus membros entre si, mas também a comunhão orgânica dela mesma com sua própria essência. ${ }^{36}$

Esta comunidade surge da partilha de "uma identidade numa pluralidade onde cada membro, desse modo, se identifica tão somente pela mediação suplementar de sua identificação com o corpo vivo da comunidade" ${ }^{37}$. Ou seja, o ser não é singular e nem plural, mas sim singular plural. Todos da comunidade testemunham, pelos olhos de um, a queda de Efrafa, a queda do fascismo, do poder/violência. Não à toa o conjunto musical é batizado com a frase "Fall of Efrafa", esclarecendo sua posição tanto contra o Estado militarizado quanto antifascista. ${ }^{38}$ Através da música, e das habilidades de se esgueirar e de utilizar os recursos que lhes cabem, ambos, banda e coelhos, encontram uma maneira de desativar a violência de Estado.

\section{Referências bibliográficas}

ADAMS, Richard. Watership Down. 40th Anniversary edition. London: Puffin Books, 2012.

AGAMBEN, Giorgio. La musica suprema. Tradução de Manuel Ignacio Moyano (de AGAMBEN, Giorgio. Che cos'è la filosofia? Macerata: Quodlibet, 2016, p. 133-146. Disponível em: <https:/ ficciondelarazon.org/2016/04/11/giorgio-agamben-lamusica-suprema-musica-y-politica/>. Acesso em 10 mar. 2020.

ANTELO, Raúl. Exceção, meios, mediação. Conferência proferida na UFSC em setembro de 2016. Fotocópia.

BENJAMIN, Walter. "Sobre alguns motivos na obra de Baudelaire". In:

Baudelaire e a modernidade. Tradução de João Barrento. Belo Horizonte: Autêntica Editora, 2015. p. 103-150.

36 NANCY, Jean-Luc. "A comunidade inoperada", 2006. p. 37.

37 Ibidem.

38 Um dos selos sob os quais o conjunto gravou e lançou seus álbuns é intitulado "Alerta Antifascista Records". 
BENJAMIN, Walter. "Sobre o conceito da História”. In: O anjo da história. Tradução de João Barrento. $2^{a}$ edição. Belo Horizonte: Autêntica Editora, 2016. p. $7-20$

BENJAMIN, Walter. "Sobre a crítica do poder como violência" In: O anjo da história. Tradução de João Barrento. $2^{\mathrm{a}}$ edição. Belo Horizonte: Autêntica Editora, 2016. p. 57-82.

BERGSON, Henri. Matéria e memória: ensaio sobre a relação do corpo com o espírito.

Tradução de Paulo Neves. São Paulo: Martins Fontes, 2006.

NANCY, Jean-Luc. “A comunidade inoperada.” In: A comunidade inoperada.

Tradução de Soraya Guimarães Hoepfner. Rio de Janeiro: 7Letras, 2006. p. 25-78.

NIETZSCHE, Friedrich. Genealogia da moral: uma polêmica. Tradução, notas e posfácio de Paulo César de Souza. São Paulo: Companhia das Letras, 1998.

PLATÃO. A República. Tradução de Carlos Alberto Nunes. $3^{a}$ edição. Belém: EDUFPA, 2000.

TOLSTÓI, Lev; GANDHI, Mahatma. "Correspondência entre L.N. Tolstói e M.K. Gandhi”. Cadernos de Literatura em Tradução, n. 9, p. 85-113. Tradução de Belkiss J. Rabello. São Paulo: Revistas USP, 2008.

\section{Músicas}

BEYOND THE VEIL. In: Elil. Composição e execução de Fall of Efrafa. Brighton: Fight for Your Mind, Alerta Antifascista, Behind the Scenes, Halo of Flies, Denovali Records Tadpole Records, 2007.

LAST BUT NOT LEAST. In: Owsla. Composição e execução de Fall of Efrafa. Brighton: Fight for Your Mind, Alerta Antifascista, Behind the Scenes, Halo of Flies, Denovali Records Tadpole Records, 2006.

Submissão: $21 / 07 / 2020$

Aceite: $20 / 10 / 2020$

https://doi.org/10.5007/2176-8552.2020.e77258 